seven or more florid episodes, and two others had florid symptoms throughout. At the other extreme 11 patients were in remission throughout. The remaining 42 patients experienced between one and six relapses during the seven years.

The authors were particularly interested in the relation between relapse and medication. The clearest relation was with non-compliance; some relapses at least seem likely to have been caused by patients stopping drugs. Of the 20 who throughout took medication as advised, 14 experienced relapses at some time during the seven years. Of the 22 who discontinued neuroleptics, 14 relapsed within 13 months. The authors plausibly suggest that continuing medication delays relapse but does not prevent it altogether. The three groups described by previous authors could thus be discerned even within this chronic series. There was a group of patients with few relapses who required little treatment with neuroleptics. Another group was "not well protected" by medication. In most, however, compliance did seem to be protective, though by no means completely.

The authors found few severe side effects, though mild tremor in arms and legs, which they regarded as extrapyramidal, was common. Ten patients had mild akathisia - motor restlessness-but only three were said to have orofacial dyskinesia. Many patients continued to receive both neuroleptics and anticholinergics despite their symptoms not having remitted.

Little is said about the quality of life of the patients in the series or about the balance between social stress and social protection. Depressive and non-specific neurotic symptoms were common, particularly in those receiving medication. In general the social performance of patients deteriorated during the seven years of follow up, though a strong correlation with the original social level remained. Frequent relapses were particularly associated with deterioration. This contrasts with an eight year follow up of long stay inpatients in three mental hospitals during the 1960s, which showed a substantial improvement in many patients, particularly associated with the level of occupation and recreation available." "Social performance is not a measure of schizophrenic deficit, though the latter is an important cause of poor social functioning. Nevertheless, symptoms such as blunting of affect and poverty of speech cannot be regarded as immutable.

The results of this survey-together with those of other studies and reviews-raise important questions about the efficacy of present community care arrangements for people who are psychiatrically disabled. Attendance at a special outpatient clinic does not guarantee a lower level of symptoms or a better standard of living. Medication tends to be continued irrespective of whether there are clear benefits to be gained. Routine attendance and continued compliance may delay relapse, but more is needed: some active outreach must be made to patients and families, and close collaboration with general practitioners, local authority staff, and voluntary organisations such as the National Schizophrenia Fellowship is also required. ${ }^{12}{ }^{13}$ Hostels and day centres must provide at least as socially rich an environment as the best mental hospitals; otherwise the whole system will fall into disrepute. ${ }^{14}$

J K WING

Professor of Social Psychiatry,

Institute of Psychiatry,

London SE5 8AF

1 American Psychiatric Association. Diagnostic and statistical manual of mental disorders (DSMIII). 3rd ed. Washington DC: American Psychiatric Association, 1980.
2 Robins LN, Helzer JE, Croughan JL, Ratcliff K. The NIMH diagnostic interview schedule: its history, characteristics and validity. In: Wing JK. Bebbington P, Robins LN, eds. What is case? The problem of definition in psychiatric community surveys. London: Grant McIntyre, 981:79-98

3 Crow TJ, Cross AJ, Johnstone EC, Own F. Two syndromes in schizophrenia and their pathogenesis. In: Henn FA, Nasrallah HA, eds. Schizophrenia as a brain disease. Oxford: Oxford University Press, 1982:196-234.

4 Murray RM, Lewis SW, Reveley AM. Towards an aetiological classification of schizophrenia. Lancel 1985;:1:1023-6.

5 Bleuler M. Die schizophenen geistesstörungen im lichte langjähriger kranken-und familiengeschichten. Stuttgart: Thieme, 1972. (Clemens SM, trans, The schizophrenic disorders: long term patient and family studies. New Haven: Yale University Press, 1978.)

6 Ciomi L. The natural history of schizophrenia in the long term. Br Y Psychiatry 1980;136:413-20. 7 Huber G, Gross G, Schüttler R. A long-term follow up study of schizophrenia: psychiatric course of illness and prognosis. Acta Psychiatr Scand 1975;52:49-57.

8 Brown GW, Bone M, Dalison B, Wing JK. Schizophrenia and social care. London: Oxford University Press, 1966. (Maudsley Monograph, No 17 .)

9 Curson DA, Barnes TRE, Bamber RW, Platt SD, Hirsch SR, Duffy JC. Long-term depot maintenance of chronic schizophrenic out-patients: the seven year follow-up of the Medical Research Council fluphenazine/placebo trial. I. Course of illness, stability of diagnosis, and the role of a special maintenance clinic. Br J Psychiatry 1985;146:464-80.

10 Wing JK, Cooper JE, Sartorius N. The description and classification of psychiatric symptoms: an instruction manual for the PSE and CATEGO system. London: Cambridge University Press, 1974.

11 Wing JK, Brown GW. Institutionalism and schizophrenia. London: Cambridge University Press, 1970.

2 Rollin HR, ed. Coping with schizophrenia. London: Deutsch, 1980:101-73.

13 Wing JK, chairman. Psychiatric rehabilitation in the 1980s. London: Royal College of Psychiatrists,

14 Social Service Committee, House of Commons. Second report on community care with special reference to adult mentally ill and mentally handicapped people. Vol 1. London: HMSO, 1985. (Chairman Mrs Renée Short.)

W

\section{Can a fetus feel pain?}

Is a fetus capable of experiencing pain? This question is one of increasing concern, and not merely to neonatologists and experts on embryonic development. Thus a meeting billed "Pain and the Fetus," organised by the Ciba Foundation might have appealed to a wide audience. In the event it was a select affair open to only two dozen invited experts from specialties including paediatrics, pathology, neurochemical pharmacology, and child psychology.

Much of the data that were presented were based on research carried out in animals and preliminary unpublished studies, so not surprisingly conclusions were guarded-even to the extent that by mid-afternoon the chairman, Professor P D Wall, an anatomist from University College London, was not prepared to say more than that the answer to the question does the fetus or premature baby feel pain was not "no" but "Who knows?" For those who would regard this as an unsatisfactory, if accurate, scientific observation the clinicians produced more tangible information.

"It is likely," said Dr C H Rodeck, an obstetrician from King's College, London, "that the fetus responds to some forms of sensory stimulation, particularly noise, changes in position, and pain." Invasive procedures such as amniocentesis and chorionic villous sampling may well have adverse effects-amniocentesis was known to be associated with an increased incidence of pulmonary hyperplasia, but it was too early to say if it results in damage to the central nervous system.

Further evidence to suggest that the neonate-if not the fetus-responds to noxious stimuli came from $\operatorname{Dr} M \mathrm{~L}$ Chiswick, a consultant paediatrician from Manchester, who reported the results of a study of basal skin conductance in neonates. (Changes in skin conductance are known to be a measure of the response to stress and are the basis of the "lie detector.") Conductance was significantly increased in babies who had undergone vaginal delivery compared with those who had been delivered by caesarean section. This and further studies led him to suggest that the longer and more 
difficult the labour the greater the arousal or "stress" to the baby. (Whether this was a good or bad thing was conjectural.)

A similar increase in conductance was also seen immediately after an infant was subjected to a heel stab to obtain a blood sample. This plus simple observation of infants in special care baby units convinced him that infants did experience pain and distress even though their responses were obviously limited.

Mention of inflicting pain on neonates introduced what was unquestionably the most clinically relevant topic of the day. Dr K J S Anand, a research fellow from the John Radcliffe Hospital, Oxford, showed that babies who undergo major surgery show large increases in a variety of different metabolic and hormonal variables. Furthermore, those infants who have surgery carried out under minimal anaesthesia show much greater rises than those who are given potent anaesthesia.

Clearly it came as a surprise to some of the audience to hear that some surgery and certain invasive procedures in neonates are carried out with only minimal anaesthesia and analgesia in some hospitals in Britain, Europe, and America. This is done on the assumption that because preterm and even term infants have no memory of pain they are probably not capable of discriminating painful from other stimuli and because anaesthetic agents may have adverse effects on the cardiovascular and respiratory systems they are best avoided. Dr Anand said that as a result of his work the paediatric anaesthetists in Oxford have changed their practice and now ensure that the babies have fully adequate anaesthesia and analgesia. They also now give more postoperative analgesia. One or two members of the audience voiced their concern that this stress at or soon after birth may have long term psychological sequelae.

There seems no doubt that the neonate and possibly the fetus is capable of "feeling" considerably more than is widely appreciated. It is to be hoped that Dr Chiswick's suggestion that those who work in special care baby units should get together and review their policies on management is promptly taken up.

TESSA RICHARDS

Assistant Editor,

$B M \mathcal{F}$

\section{National Health Service: control of nursing manpower}

Whether or not the National Health Service is "safe in its hands," a government committed to a reduction in public expenditure might be expected to look critically at nursing manpower. In the year 1983-4 nurses' salaries cost $£ 3487$ million, accounting for $34 \%$ of the NHS budget - and nearly $3 \%$ of all public expenditure. ${ }^{1}$ Nursing manpower in this context includes all grades of qualified staff, learners (pupil and student nurses), and unqualified staff (nursing auxiliaries). Nursing auxiliaries are quite properly included in the nursing budget, but it is unfortunate that yet another government document classifies them as "nurses." Not only does this put a group with little or (in most cases) no training on the same level as those who have undergone training but it also leads the public to think that they, and their relatives, are being cared for by qualified staff.
One of the claims of the present government is that expenditure on nursing manpower has increased during its term of office. Certainly between 1976 and 1983 there was a $16 \%$ increase in the bill for nursing salaries in England, with similar increases in Scotland and Wales. In real terms, however, this figure falls to $9 \%$ when allowance is made for the reduction in working hours to $371 / 2$ a week in 1980 . Furthermore, in England between 1978 and 1983 the number of hospital patients increased by roughly $12 \%$ and outpatient attendances increased by $7 \%$. Turnover in the acute sector has speeded up, meaning that patients in these beds require more nursing care, as do the patients aged 65 and over, who now make up over one quarter of all acute admissions. Technological innovations and the need for periods of postregistration training to enable nurses to work in specialist areas have reduced the hours available for direct patient care. Hence the claim that increased numbers have improved care has to be viewed with some scepticism. Finally, while numbers of nurses in deprived parts of the NHS, such as those caring for the aged, mentally ill, and handicapped, have increased, their numbers started from a pitifully low base.

Against that background a report published this summer from the Comptroller and Auditor General has shown that in most health authorities the planning and control of nurse manpower is haphazard. Various methods are available for estimating nursing manpower needs, either "topdown" (that is, by the use of measures of output and activity) or "bottom up" (that is, by the use of professional nursing judgment about the number of nurses required to provide care). In practice, most authorities use either a historical base or one swayed by the availability of resources to determine how many nurses to employ. Few seem to have made any serious attempt to consider the most suitable "mix" of grades of staff in relation to the type of patient or aspect requiring care. Some authorities are now attempting to develop performance indicators, which may help, and the DHSS has just announced a group to review "skill mix," but much more effort is needed.

The report suggests several ways in which substantial savings might be made. The first of these is the time allowed for shift overlap-which in the sample studied varied from two to six hours. The National Audit Office report considers 90 minutes (to include a meal break) to be adequate, and its appendix 9 shows the money that could be recouped from a reduction in this time. Clearly the suggestions warrant careful study, but account needs to be taken of what is done by nurses in that overlap period. In some cases the extra hands are needed to get heavy patients up and dressed; in others the time is used for teaching learners. No doubt some rosters might be altered, but local circumstances (such as availability of public transport, especially late at night) may be a hindering factor. Wherever savings are being proposed staff organisations will want assurances that the attempt to save money will not disadvantage either the patients or the nurses.

Another comment made in the report is that in some hospitals staff were employed on a grade higher than that needed by the task. The explanation seemed to be the lack of suitably qualified staff. Again the implications for the care of patients might be sinister: the cheap solution is for authorities to employ untrained staff in these circumstances, but that temptation should be resisted.

The study uncovered the fact that nurses were still carrying out work that could be considered "non-nursing" and that elimination of these tasks would produce a 